\title{
Usuários idosos e sua relação com celulares: RBS e as contribuições e oportunidades para o Design
}

Nathan Martins Fernandes;

Larissa Raquel Ferro Marques;

Luis Carlos Paschoarelli

resumo:

Idosos apresentam diminuição de sua capacidade regenerativa, caracterizando novas demandas e necessidades, especialmente durante a interação com os atuais sistemas tecnológicos. Alguns telefones celulares foram desenvolvidos visando atender esses usuários, mas a interação idososcelulares depende da produção científica das diferentes áreas do conhecimento. O presente estudo objetivou compreender o estado da arte sobre os principais problemas encontrados na interação idosos-celulares, aplicando uma Revisão Bibliográfica Sistemática (RBS). Foram realizadas buscas em 03 bases de dados eletrônicas, sendo levantadas 98 referências que, após a aplicação de critérios e filtros, decorreram na análise de 22 importantes estudos. Os resultados responderam a questão de pesquisa e os objetivos; e apontaram diversos problemas físicos, cognitivos e emocionais, o que representa um importante argumento e uma contribuição expressiva para os estudos científicos na área do Design e Experiência do Usuário.

\section{palavras-chave:}

Idoso; Design Ergonômico; Celulares; Experiência do Usuário; Revisão Bibliográfica Sistemática 


\section{Introdução}

A evolução da vida humana apresenta diferentes fases, cada uma com suas características e peculiaridades, sendo a fase dos idosos aquela cujos indivíduos apresentam diminuição na capacidade regenerativa e, portanto, em suas capacidades físicas e cognitivas. Esta condição reflete em novas necessidades e demandas, as quais influenciam - especialmente - a forma como esses indivíduos interagem com produtos e sistemas tecnológicos.

Além disto, há também o denominado Envelhecimento Populacional, então representado pelo aumento da taxa da população idosa na sociedade (graças aos avanços da medicina, urbanização, higienização e nutrição) o que representa um grande avanço social (MENDES et al., 2005). De acordo com o Instituto Brasileiro de Geografia e Estatística (IBGE), no censo brasileiro de 2010 a proporção de idosos na população era da ordem de $10 \%$, mas estima-se que tal representatividade chegará a $20 \%$ em 2033 (IBGE, 2010). Maior longevidade, porém, não representa melhor qualidade. Na verdade, é necessário que haja uma atenção dedicada ao melhoramento da qualidade de vida e manutenção da autonomia destas pessoas.

No âmbito das áreas tecnológicas, particularmente no campo do Design, isto deve ser considerada uma oportunidade estratégica para o desenvolvimento de novos artefatos e sistemas, buscando atender as necessidade e expectativas dos idosos; e permitindo que vivam plenamente todas suas atividades com elevado bem-estar dos indivíduos.

Este bem-estar está relacionado a viver com qualidade, ao qual a WHO (2020) define como a manutenção e conservação de cinco habilidades: aprender; tomar decisões; cuidar de seu corpo, incluindo as necessidades básicas (alimentar-se, vestir-se, tomar banho, etc.); manter a mobilidade; construir e manter relacionamentos e contribuir como cidadão. $\mathrm{O}$ uso de tecnologias é essencial para complementar a autonomia destas habilidades (UNITED NATIONS, 2013), e dentre o escopo de objetos que podem auxiliar várias destas tarefas destacam-se os telefones móveis, ou celulares, capazes de proporcionar ao usuário acesso a comunicação remota pela comunicação por voz e vídeo em tempo real, além de informações via internet.

Há evidências de uma contribuição positiva na qualidade de vida dos idosos quando são inseridas tecnologias para auxiliar no seu cotidiano (BRIEDE-WESTERMEYER et al., 2020), porém, os projetos de interfaces de celulares, do tipo smartphone, não levam estas pessoas em consideração e, ao negligenciá-los, oferecem interfaces e experiências incompletos e desafiadores para muitos destes idosos/usuários (ZHAO, MEN, 2016). Muitas interfaces já foram desenvolvidas para tentar preencher esta lacuna, mas a maioria delas são reprovados em testes de usabilidade (ANAM, ABID, 2020).

As dificuldades enfrentadas pelos usuários podem ser de ordem física, cognitiva e emocional (CHIRAYUS, NANTHAAMORNPHONG, 2019; LIU et al., 2016; JAKKAEW, HONGTHONG, 2017; FA, SOO, 2018; ZAREEI et al., 2016; ANJOS, GONTIJO, 2015; SHA, LI, CHANG, 2017; FUGLERUD, CHAN, SØRLI, 2018; FANG, HONG, 2018), dado a imensa variedade de causas que acarretam tais constrangimentos. Portanto, faz-se necessário aumentar o número de estudos que envolvam compreender e aprimorar a relação usuário $\mathrm{x}$ artefato entre idosos e celulares.

O presente estudo objetivou compreender o estado da arte sobre os principais problemas especialmente relacionados aos aspectos físicos, cognitivos e emocionais - encontrados na interação idosos-celulares, aplicando uma Revisão Bibliográfica Sistemática (RBS).

\section{Revisão Bibliográfica Sistemática}

Este estudo caracteriza-se por uma abordagem qualitativa (GRUPO ĂNIMA EDUCAÇÃO, 2014; PEREZ, 2020) e exploratória de revisão do estado da arte. Para tanto, foram utilizadas as seguintes bases de dados: Scopus, Science Direct e Web of Science. Para a organização dos artigos e detecção de duplicatas utilizou-se o software Mendeley, e para a tabulação das informações utilizou-se a plataforma Google Planilhas.

Para a realização da revisão, adotou-se o procedimento metodológico descrito por Botelho, Cunha e Macedo (2011), caracterizado por seis etapas:

- Identificação do tema e questão de pesquisa; 
- Critérios de inclusão e exclusão;

- Identificação dos estudos pré-selecionados e selecionados;

- Categorização dos estudos selecionados;

- Análise e interpretação dos resultados e a apresentação da revisão/síntese do conhecimento, que serão adaptadas, mescladas e apresentadas no tópico 03 (Resultados e Discussões).

\subsection{Identificação do tema e questão de pesquisa}

Levando em consideração o aumento da expectativa de vida, que acarreta em uma maior porcentagem de indivíduos que vivem além dos 60 anos no Brasil e no mundo inteiro, é necessário que haja uma atenção especial quanto aos cuidados e necessidades destas pessoas.

Portanto, a questão de pesquisa adotada para o presente estudo foi: Quais são as principais barreiras dos usuários idosos na utilização de celulares?

\subsection{Critérios de inclusão e exclusão}

A execução da revisão seguiu o padrão de busca nas bases de dados por todos os artigos publicados entre 2015 a 2020, incluindo artigos de congressos indexados e revistas, porém excluindo os capítulos de livros.

Também optou-se em excluir os estudos ao qual não possuíam idosos como sujeitos de pesquisa ou população, bem como os estudos que não tratavam das relações cotidianas com os celulares, ou seja, foram excluídos os estudos que, de alguma forma, utilizavam dos telefones para adaptar novas funções ou criar novas tecnologias que não as previamente determinadas pelo fabricante.

Os idiomas aceitos para inclusão na pesquisa foram Português e Inglês. A pesquisa foi executada em busca das palavras chaves na categoria Tópicos, que inclui Título, Resumo e Palavras-chave.

\subsection{Identificação dos estudos pré-selecionados e selecionados}

O estudo foi realizado nas seguintes bases de dados, com as respectivas strings:

- Scopus, utilizando-se da string: "ageing" OR "elderly" AND "phone" AND "user experience" OR "usability", retornando 75 artigos;

- Science Direct com a string: ((“ageing” OR "elderly")) AND ((“phone”)) AND ((“user experience" OR "usability")), retornando 19 resultados;

- Web of Science por meio da string ("ageing" OR "elderly") AND ("phone") AND ("user experience" OR "usability"), retornando 4 resultados.

Estes 98 artigos encontrados foram submetidos ao primeiro filtro: a Leitura de título e checagem de duplicatas, restando 24 estudos; ao segundo filtro: leitura de resumo e conclusão. Neste caso, excluíram-se todos que não se referiam diretamente a estudos envolvendo a usabilidade de celulares por usuários idosos. Os artigos encontrados nas bases de dados Science Direct e Web of Science foram todos desconsiderados desta revisão (visto os critérios de exclusão previamente mencionados), restando desta etapa a seleção de 22 artigos para leitura completa.

\subsection{Categorização dos estudos selecionados}

Os estudos selecionados foram numerados para posterior avaliação, conforme apresentado na Tabela 01 e seguiram uma classificação a partir dos problemas identificados, sendo eles de ordem física, cognitiva, emocional, entre outros aspectos. 
Tabela 01. Títulos e autores dos estudos selecionados.

\begin{tabular}{|c|c|c|}
\hline$n^{\mathbf{0}}$ & Título & Autores \\
\hline 01 & Larger Chinese text spacing and size: Effects on older users' experience & Hou et. al. (2018) \\
\hline 02 & Research on Smart Phone Interfaces for the Elderly Based on Ergonomics & Fa e Soo (2018) \\
\hline 03 & Heuristic evaluation of the smartphone applications in supporting elderly & Garcia e Lara (2018) \\
\hline 04 & $\begin{array}{l}\text { A Systematic Mapping Review: Mobile User Interface Design Guidelines for } \\
\text { the Elderly with Cognitive Impairments }\end{array}$ & $\begin{array}{l}\text { Chirayus e } \\
\text { Nanthaamornphong } \\
(2019)\end{array}$ \\
\hline 05 & $\begin{array}{l}\text { A study of the factors affecting the usability of smart phone screen protectors } \\
\text { for the elderly }\end{array}$ & Liu et al. (2016) \\
\hline 06 & Requirements elicitation to develop mobile application for elderly & $\begin{array}{l}\text { Jakkaew e Hongthong } \\
\text { (2017) }\end{array}$ \\
\hline 07 & Evaluate the usability of the mobile instant messaging software in the elderly & $\begin{array}{l}\text { Tzu-ning, Po-liang e } \\
\text { Po-lun (2017) }\end{array}$ \\
\hline 08 & $\begin{array}{l}\text { Co-creation with older adults to improve user-experience of a smartphone } \\
\text { self-test application to assess balance function }\end{array}$ & Mansson et al. (2020) \\
\hline 09 & $\begin{array}{l}\text { Experimental study: The effects of mobile phone icons characteristics on } \\
\text { users' age groups }\end{array}$ & $\begin{array}{l}\text { Ghayas, Al-Hajri e } \\
\text { Sulaiman (2018) }\end{array}$ \\
\hline 10 & $\begin{array}{l}\text { Smartphone Text Input Method Performance, Usability, and Preference with } \\
\text { Younger and Older Adults }\end{array}$ & $\begin{array}{l}\text { Smith e Chaparro } \\
(2015)\end{array}$ \\
\hline 11 & $\begin{array}{l}\text { Analysis and research on the gesture-based interaction of touch-screen } \\
\text { smartphones for the elderly based on ergonomics }\end{array}$ & Zhao e Men (2016) \\
\hline 12 & Usability study of smart phone messaging for elderly and low-literate users & Anam e Abid (2020) \\
\hline 13 & $\begin{array}{l}\text { Assessing the usability and ergonomic considerations on communication } \\
\text { technology for older Malaysians }\end{array}$ & Zareei et al. (2016) \\
\hline 14 & $\begin{array}{l}\text { Mobile phone use by the elderly: Relationship between usability, social } \\
\text { activity, and the environment }\end{array}$ & $\begin{array}{l}\text { Briede-Westermeyer } \\
\text { et al. }(2020)\end{array}$ \\
\hline 15 & Heuristic evaluation of the smartphone applications in supporting elderly & $\begin{array}{l}\text { Salman, Ahmad e } \\
\text { Sulaiman (2018) }\end{array}$ \\
\hline 16 & $\begin{array}{l}\text { Development of a framework to improve the use of mobile devices by the } \\
\text { elderly }\end{array}$ & Arruda et al. (2018) \\
\hline 17 & $\begin{array}{l}\text { Usability and accessibilty guidelines for mobile phone interface for elderly } \\
\text { [Recomendações de usabilidade e acessibilidade para interface de telefone } \\
\text { celular visando o público idoso] }\end{array}$ & $\begin{array}{l}\text { Anjos e Gontijo } \\
(2015)\end{array}$ \\
\hline 18 & $\begin{array}{l}\text { Research on interaction design of intelligent mobile phone for the elderly } \\
\text { based on the user experience }\end{array}$ & Yang e Huang (2015) \\
\hline 19 & Color affects the usability of smart phone icon for the elderly & Sha, Li e Chang \\
\hline
\end{tabular}




\begin{tabular}{r|l|l}
\hline $\mathbf{2 0}$ & $\begin{array}{l}\text { Studying older people with visual impairments using mainstream } \\
\text { smartphones with the aid of the Ezismart keypad and apps }\end{array}$ & $(2017)$ \\
\hline $\mathbf{2 1}$ & $\begin{array}{l}\text { Designing interface for elderly adults: Access from the Smartphone to the } \\
\text { world }\end{array}$ & $\begin{array}{l}\text { Fuglerud, Chan e Sørli } \\
(2018)\end{array}$ \\
\hline $\mathbf{2 2}$ & High-aged using smart phone interface gesture operation research & Fang e Hong (2018) \\
\hline
\end{tabular}

Fonte: elaborada pelos autores.

\section{RESULTADOS E DISCUSSÕES}

A produção acadêmica encontrada sobre o tema não segue uma constância crescente no recorte temporal (Figura 01). O ano de maior publicação foi 2018, com 8 estudos; seguido de 2015, com 4 estudos; em 2016, 2017 e 2020 com 3 estudos e em 2019 com apenas uma publicação.

Figura 01. Linha do tempo das publicações selecionadas.

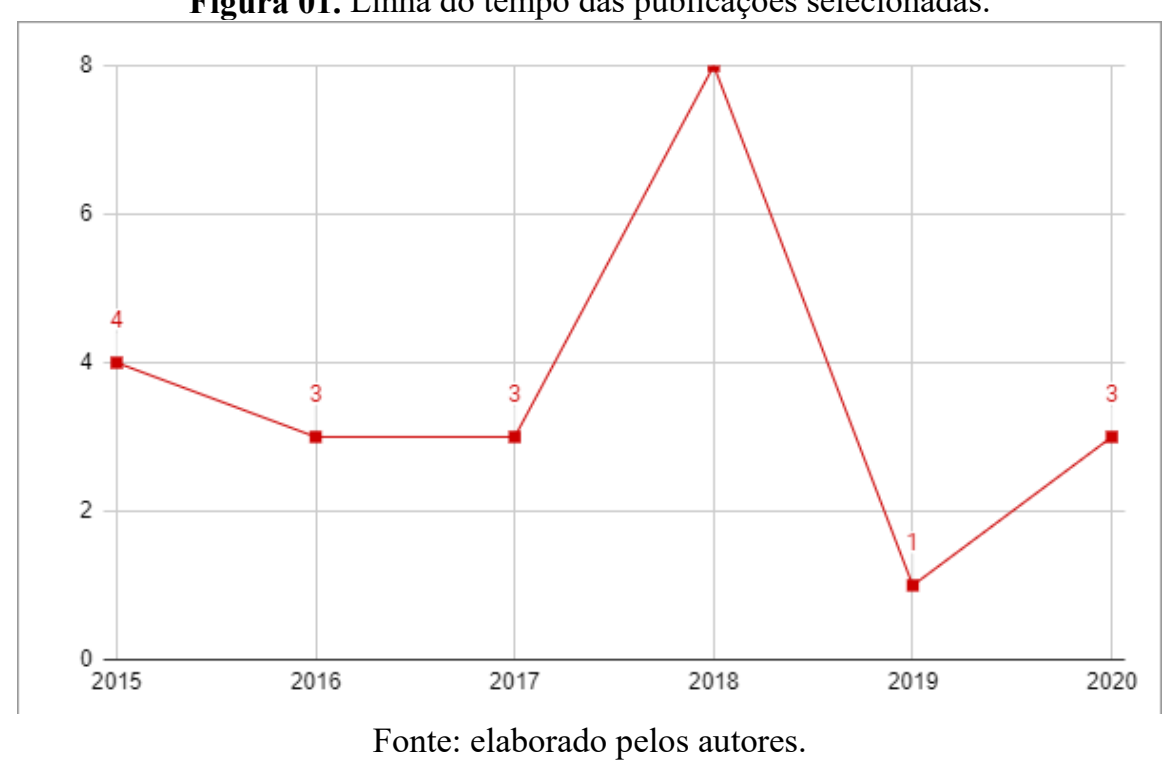

Após a leitura e revisão dos estudos, chegou-se a alguns pontos chave mencionados pelos autores (Figura 02), que citam diversos problemas de ordem física, cognitiva e emocional envolvendo idosos e celulares.

Figura 02. Infográfico de tópicos envolvendo as relações entre a pessoa idosa e celulares. 


\section{Pessoa Idosa}

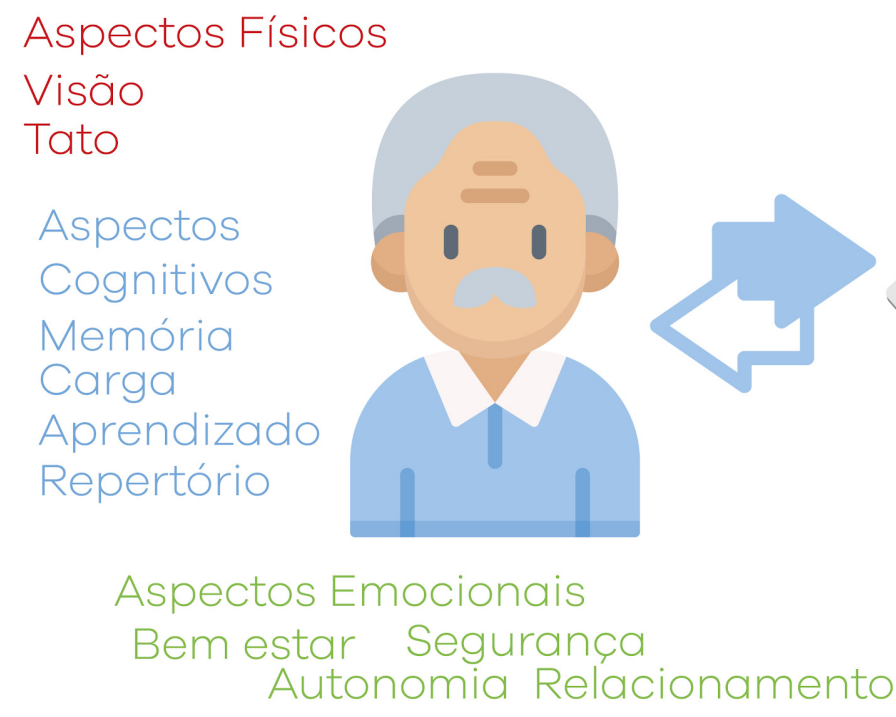

\section{Celulares}

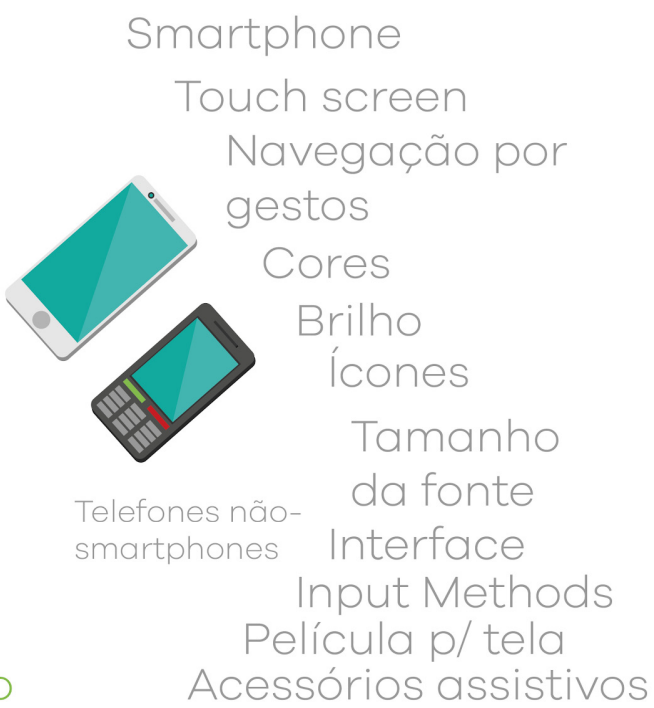

Fonte: elaborada pelos autores.

Quanto uma abordagem física, Hou et.al. (2018) abrangeram um experimento utilizando-se de software de Eye Tracking, seguido de questionário. Os resultados apontam que a usabilidade na leitura de caracteres chineses é melhorada se o tamanho for 20 pixels e 1.4 de espaçamento entre linhas, já o espaçamento entre palavras prejudica a leitura. Portanto, os autores apresentam recomendações de design para tamanhos de fontes, espaçamentos entre palavras e entre linhas de acordo com a tarefa a ser executada pelo idoso, como ler instruções ou manuais, notícias ou livros, materiais de leitura intensiva ou pesquisar informações.

Ainda no âmbito da interação física, Liu et. al. (2016) realizaram um estudo experimental sobre os protetores de tela touch-screen, as películas, e a sensibilidade ao toque dos idosos. Concluíram que a película de vidro temperado de espessura $0.35 \mathrm{~mm}$ teve melhor performance em relação aos outros protetores de tela que utilizam como material base o PET, mas as avaliações qualitativas dos usuários apontaram a preferência ao material translúcido por atenuar e suavizar a luz na tela. Já quanto a entrada de informação, Smith e Chaparro (2015) realizaram um experimento com idosos e pessoas que nunca tiveram acesso a celulares touch-screen, por meio do qwerty digital na tela do aparelho, tracing, qwerty físico externo ao celular e comando por voz. Destes, o comando por voz foi o melhor método de entrada de texto para pessoas sem experiência com celulares, em seguida o qwerty físico (um mini teclado) por se assemelhar ao teclado de computador. Neste sentido, considerando a importância da entrada de informações, por meio de gestos, Zhao e Men (2016) fizeram um levantamento de uso de operação por gestos e capacidades dos idosos em operá-lo, e concluíram que o projeto dos gestos podem melhorar se houverem maiores pesquisas correlacionando cientificamente os dados encontrados.

No que tange a interação por contato com a tela dos celulares e o uso da extremidade dos membros superiores, Arruda et. al. (2018) realizaram testes com usuários idosos e perceberam grande dificuldade em executar o movimento de zoom, sugerindo o uso de uma barra lateral para ser operada com apenas um dedo. Também percebe-se a dificuldade em inserir os textos no teclado, devido seu tamanho, e sugere-se a função de inserção de texto por fala como padrão. Propõe-se alternativas de comandos por gestos para minimizar falhas de usabilidade. Outro estudo que realiza abordagem correlata é descrito por Fang e Hong (2018), os quais projetaram comandos por gestos para utilização de algumas funções mais intuitivas, por meio de testes comprovaram relevância para os comandos projetados. Percebeu-se a dificuldade dos idosos em utilizar funções que precisam de dois dedos, como o ZOOM IN e ZOOM OUT. Recomenda-se a criação de gestos que utilizem apenas 1 dedo. 
Com relação ao emprego de cores, Sha, Li e Chang (2017) realizaram um estudo por meio do experimento conduzido com Eye Tracking, checaram a eficiência de ícones flat, monocromáticos e multicoloridos com idosos. Os resultados apontam que para ícones multicoloridos, a variedade de cores pode aumentar o fardo cognitivo e comprometer a memória do usuário. Porém, entre os idosos mais velhos, alguns preferiram os multicoloridos devido suas experiências visuais. Os autores sugerem estudos futuros que possam abordar outros fatores como brilho e contraste; e perceberam que ícones monocromáticos são mais concisos que os multicoloridos.

Por fim, Anjos e Gontijo (2015) realizaram um estudo sobre a compreensão de ícones e notaram uma série de recomendações: idosos necessitam de tipografia grande; preferencialmente informações monocromáticas; ícones representados por elementos conhecidos; interface com feedback tátil, visual e sonoro; navegação clara; atalhos para executar tarefas mais rapidamente; funções e comandos fáceis de identificar e sem dupla interpretação; quanto à rolagem da tela, deve-se colocar indicadores o usuário; deve-se adequar ao contexto de mobilidade; respeitando as limitações físicas do aparelho, a interface não miniaturizada; possibilitar o redimensionamento do texto e interface, que deve possibilitar pausar, parar ou ocultar um conteúdo que se mova ou pisque; apresentar o menor número possível de telas; selecionando opções ao invés de digitá-las; evitar abreviaturas e jargões técnicos; fornecer suporte a navegação interrompida, retornando de onde parou; rótulos ou instruções quando o sistema requer uma resposta; automaticamente detectar erros de entrada de dados e apresentar uma mensagem, possibilitando a verificação e correção de quaisquer informações que submeterem. Seus estudos verificaram que $56 \%$ dos participantes preferem tela grande e $82 \%$ tela não sensível ao toque.

Quanto a abordagem cognitiva da interação idosos-celulares, Ghayas, Al-Hajri e Sulaiman (2018) confirmaram hipótese acerca da compreensão de ícones por idosos, ao testar a compreensividade, constataram a maior dificuldade dos idosos em interpretar os ícones dos celulares de modo geral, bem como distinguir os ícones que se encontram próximos na interface, e ressaltaram que para aprimorar a usabilidade dos telefones, é positivo que no futuro os ícones sejam de maior facilidade de aprendizado por jovens e idosos.

Ainda nesta abordagem, Fuglerud, Chan e Sørli (2018) prototiparam e avaliaram um acessório assistivo capaz de acoplar-se ao smartphone e torná-lo age friendly. Voltado a idosos com problemas de visão, o produto EziSmart trata-se de um case ao qual se insere o celular, tornando-o similar ao formato flipper, que ao abrir dá ao usuário acesso à tela do aparelho e a um teclado alfanumérico físico. Em seu exterior, possui botões de chamada rápida e o "SOS". Seis participantes do experimento se submeteram a um treinamento para utilizar o acessório e deram feedback qualitativo positivo. Conclui-se que o Acessório e app são capazes de auxiliar na superação de limites de aprendizado no que tange a utilização de celulares por idosos com problemas de visão e baixa visão. E outro aspecto cognitivo, relacionado à adaptação ao produto, é descrito por Tzu-ning, Po-liang e Po-lun (2017), os quais realizaram uma avaliação de softwares de mensagem instantânea (LINE) em celulares por idosos através de um experimento seguido de questionário e Escala Likert, concluíram que houve maior aceitação e utilização a medida que os usuários se acostumaram com o smartphone e sua interface.

Salman, Ahmad e Sulaiman (2018) avaliaram os aplicativos de câmera e alarme de um Samsung Galaxy J7 entre especialistas (não houve participação do usuário) e elencaram seis problemas aos quais os idosos podem vir a enfrentar: 1. Para que o alarme toque todos os dias, é necessário apertar todos os dias da semana separadamente e com isso podem desmarcar acidentalmente; 2. Sendo necessário tocar 7 vezes na tela; 3 . A função do alarme está escondida dentro do relógio; 4. Tocar no ícone do alarme programado desativará sem que seja dada alguma mensagem de feedback, ao qual poderia desativar acidentalmente sem perceber; 5. As câmeras apresentam botões com tamanhos diferentes, que viola o princípio da heurística da consistência e 6 . O botão Mode é menor e quadrado, violando o mesmo princípio heurístico. $\mathrm{O}$ estudo utilizou-se da opinião de 5 especialistas na área de User Interface para apontamento de possíveis problemas de usabilidade. Com a participação destes profissionais os autores afirmam que é possível detectar cerca de $75 \%$ dos problemas. Já Mansson et. al. (2020), criaram um aplicativo de incentivo a exercícios para prevenção de quedas, inserindo o usuário idoso em um ambiente de cocriação de uma aplicação que o tem como público-alvo. Utilizaram o método de UX Honeycomb para feedback qualitativo e relatou-se uma interação positiva dos participantes durante a cocriação, que demonstraram interesse em utilizar o aplicativo e entender o seu funcionamento. 
No âmbito emocional, Garcia e Lara (2018) realizaram um estudo de caso de um app chamado MobiCare, e então procederam com a avaliação por meio de questionários. O aplicativo foi criado por meio de um briefing de necessidades realizado ao efetuar entrevistas com especialistas e foi posteriormente submetido à avaliação heurística que apontou suas principais dificuldades e grau de severidade. Os autores concluíram que o aplicativo contribui com os idosos para utilizarem celulares e cuidarem de sua saúde através de lembretes, mas pode ser uma ferramenta útil a cuidadores e familiares, sugerem futuramente a implementação da função álbum de fotos para que os idosos se sintam emocionalmente ligados ao aplicativo.

Quanto a criação de empatia entre usuário e artefato, Zareei et. al. (2016) aplicaram um questionário com 400 idosos na Malásia, obtendo 303 respostas válidas sobre a utilização de smartphones, nas quais constatam que raramente este grupo utiliza de aplicativos de mensagem instantânea, concluindo que o design dos telefones deveriam considerar uma maior empatia para criação de projetos mais "user-friendly" para idosos. E, por fim, Yang e Huang (2015) concluem que a User Experience do idoso em relação aos smartphones está intimamente ligado ao próprio idoso, suas emoções, necessidade de atenção, e compreensão de suas emoções, enfatizam a necessidade projetual de se apegar aos aspectos emocionais dos usuário.

Outros estudos realizaram testes de usabilidade, como por exemplo Jakkaew e Hongthonh (2017), com avaliação heurística, personas e elicitação para avaliar a mesclagem de técnicas de obtenção de dados dos usuários para a criação de projetos e, através do feedback obtido, consideraram eficazes para assertividade de projetar aplicativos para idosos. Anam e Abid (2020) fazem o levantamento de problemas de usabilidade encontrados nos celulares para o público idoso e de baixa instrução. Concluem que estes grupos de usuários têm medo de utilizar os smartphones devido a interface e métodos de interação, e propõem um sistema de mensagens para atender as necessidades destas pessoas e minimizar suas fobias e preconceitos. Sugerem a criação de uma interface simplificada no futuro para submissão aos métodos experimentais. Ainda neste tema, Briede-Westermeyer et al. (2020) prototiparam um questionário que associasse utilidade, satisfação e facilidade de uso (USE), validado por um grupo de 10 especialistas entre geriatras, profissionais de saúde pública, designers industriais e psicométricos. Conclui-se que o nível de interação dos idosos com celulares está associado positivamente com a atividade social do indivíduo, e o uso de telefones celulares por idosos está diretamente e estatisticamente correlacionado com o nível de educação, a renda familiar, e o nível de saúde, bem como inversamente proporcional à idade. Percebeu-se que a usabilidade foi maior em idosos mais jovens (grupo de 60 a 69 anos).

Quanto aos aspectos funcionais, Lai e Lai (2015) aplicaram entrevistas e concluíram que as funções dos telefones, para os idosos, dividem-se em três, sendo estas: Necessidades básicas: fazer e receber chamadas, desfrutar conteúdo audiovisual, acessar a internet, tomar notas, tirar fotos, aprender coisas na internet, fazer chamadas de emergência, ajustar alarmes. Menos necessárias: ler notícias online e escrever e-mails. Sem utilidade para idosos: calendários e planejadores. Também concluiu-se que os idosos utilizam os telefones por duas razões: conveniência e acesso à internet. Por fim, dividiuse os idosos em dois grupos: aqueles que não vêem necessidade de um smartphone, estando satisfeitos com celulares convencionais, e aqueles que preferem smartphones, mas estariam mais felizes se estes atendessem melhor suas necessidades. Suas maiores dificuldades com smartphones são: discagem acidental, telas pequenas, sistema de chamada de emergência complexo, mudanças de configuração muito complicadas, sensibilidade do touch-screen, erros de digitação, confusão sobre o significado dos ícones dos aplicativos, e maiores problemas gerados pela falta de repertório e histórico de uso.

No âmbito das três abordagens - física, cognitiva e emocional - Fa e Soo (2018) realizaram um levantamento baseado no feedback de usuários idosos de celulares acerca de suas demandas, levando em consideração princípios de interação humano computador. Entre outras contribuições, ressaltaram que o desenvolvimento tecnológico exerce profundo impacto sobre o meio ambiente e o estilo de vida dos idosos, portanto é necessário atribuir maior importância a este grupo de consumo a fim de criar um ambiente de interação amigável do produto. E no âmbito dos estudos de revisão. Chirayus e Nanthaamornphong (2019) efetuaram uma revisão bibliográfica sistemática e levantaram 12 artigos, de onde elencaram recomendações para o desenvolvimento de aplicativos para idosos com ênfase nos aspectos cognitivos. Suas conclusões são de que há lacunas a serem preenchidas pelos desenvolvedores e designers interessados em criar sistemas mobile para melhorar a usabilidade em idosos com problemas cognitivos. Os autores afirmam que há pouca pesquisa na área específica e 
reforçam a urgência em aumentar os esforços de pesquisa dado o envelhecimento rápido da população mundial. Utilizaram-se dos bancos de dados ACM e IEEE, de 2008 a 2019.

Tendo em vista a ampla gama de resultados para análise, é provável que não haja uma solução universal a todos os casos, que preencha as necessidades de todos os usuários idosos. Há diferenças de faixa etária entre os idosos combinadas a níveis diferentes de perdas de cognição. Algumas destas pessoas preferem os celulares não-smartphones, uma causa provável é a perda da sensibilidade ao toque nos dedos, e os botões destes celulares dão um feedback natural ao usuário, que o percebe melhor que a touch-screen dos smartphones.

Observa-se que há um amplo interesse por estudos que aprimorem a compreensão do usuário com o objeto fruto de um projeto, e com os celulares não é diferente. Diferentes modelos de smartphones age friendly são lançados no mercado objetivando satisfazer estas pessoas de seus anseios, e o Design como área pode desempenhar um papel essencial na busca da solução de tal projeto.

\section{Considerações Finais}

A população idosa é composta por um grupo cujas demandas e necessidades são amplas e heterogêneas. Portanto, parece sensato haver interesse constante na melhoria da qualidade de vida destas pessoas, com a iniciativa de ações advindas de diferentes áreas do conhecimento.

O propósito principal do presente estudo foi revisar referências mais recentes (últimos 5 anos) e sondar as abordagens e recomendações apresentadas. Os resultados apontaram uma preocupação real, não apenas para designers, mas também para desenvolvedores de software e outras áreas de tecnologia e saúde. Observou-se ainda uma unanimidade dos 22 artigos revisados, com relação a expansão de conhecimentos sobre a relação entre os idosos e os artefatos de comunicação e tecnologia. Por serem ferramentas de comunicação à distância em tempo real, há benefícios sociais e emocionais imensuráveis, sendo uma tarefa essencial garantir que o usuário não desista de utilizar tais artefatos, em decorrência de sua complexidade de uso.

Os idosos são indivíduos que, para fins científicos e mercadológicos, apresentam características próprias. Neste sentido, há muitas variáveis em cada pessoa que podem influenciar na maior ou menor autonomia, e consequente complexidade das soluções propostas para atender cada necessidade particular. Associam-se a isto, a perda cognitiva e da sensibilidade ao toque, com fatores gerais como instrução e alfabetização e até mesmo o repertório dos indivíduos usuários. Tal complexidade deve ser atentamente observada, por designers, ou por equipes multidisciplinares.

Como sugestões de estudos futuros, destacam-se a criação de uma classificação das intervenções nas interfaces (exemplo: tela, meio de entrada, operação por gestos, ícones, tamanho de celular), a inclusão de mais bases de dados a fim de que se possa abranger o mais próximo da totalidade de problemas já notados; a replicação de estudos em outras regiões de culturas diferentes (por exemplo: tamanho da fonte para leitura de caracteres ocidentais), como fizeram Hou et. al. (2018) em relação aos caracteres chineses, ou ainda o experimento proposto por Zhao e Men (2016) para projetar novos comandos por gestos.

Por fim, é sugerido o avanço na própria presente Revisão, incluindo mais bases de dados e um escopo maior de tempo, a fim de que se possa compreender a evolução histórica do produto e dos problemas de usabilidade que o acompanham.

\section{Agradecimentos}

Este estudo foi desenvolvido com o apoio da Coordenação de Aperfeiçoamento de Pessoal de Nível Superior - CAPES (Processos 88887.484258/2020-00 e 88887.484276/2020-00) e do Conselho Nacional de Desenvolvimento Científico e Tecnológico (Processo 304619/2018-3). 
Elderly users and their relationship with cell phones: SMR and the contributions and opportunities for Design

\begin{abstract}
:
Elderly present a decrease in their regenerative capacity, characterizing new demands and needs, especially during the interaction with the technological systems. Some cell phones were developed to serve these users, but the elderly-cell phone interaction depends on the scientific production of different areas of knowledge. The present study aimed to understand the state of the art on the main problems encountered in the interaction between elderly and cell phones, applying a Systematic Mapping Review (SMR). Searches were carried out in 03 electronic databases, and 98 references were collected, which, after applying criteria and filters, 22 important studies were analyzed. The results answered the research question and the objectives; and pointed out several physical, cognitive and emotional problems, which represents an important argument and an expressive contribution to scientific studies in the area of Design and User Experience.
\end{abstract}

Keywords: Elderly; Ergonomic Design; Cell phones; User Experience; Systematic Mapping Review.

\title{
Referências bibliográficas
}

ANAM, R.; ABID, A. Usability Study of Smart Phone Messaging for Elderly and Low-literate Users.

International Journal Of Advanced Computer Science And Applications, [s.I.], v. 11, n. 3, p. 108-115, mar. 2020. The Science and Information Organization.

http://dx.doi.org/10.14569/ijacsa.2020.0110313.

ANJOS, T. P.; GONTIJO, L. A. Recomendações de usabilidade e acessibilidade para interface de telefone celular visando o público idoso. Production, [s.l.], v. 25, n. 4, p. 791-811, out./dez. 2015. Cambridge University Press (CUP). http://dx.doi.org/10.1590/0103-6513.091312.

ARRUDA, D. P.; ANDRADE, M. V. A.; ROCHA, M. N.; VEGI, L. F. D. M.; FEHLBERG, F. C. Development of a Framework to Improve the use of Mobile Devices by the Elderly. 2018 XLIV Latin American Computer Conference (clei), [s.I.], p. 334-343, out. 2018. IEEE. http://dx.doi.org/10.1109/clei.2018.00048.

BOTELHO, L. L. R.; CUNHA, C. C. A.; · MACEDO, M. O método da revisão integrativa nos estudos organizacionais. Gestão e Sociedade. 'Belo Horizonte, v.5, n. 11, p. 121-136 ' maio-ago. 2011 ' ISSN 1980-5756. Disponível em:

<http://www.gestaoesociedade.org/gestaoesociedade/article/view/1220/906>. Acesso em: 12 maio 2020.

BRIEDE-WESTERMEYER, J. C.; PACHECO-BLANCO, B.; LUZARDO-BRICEÑO, M.; PÉREZ-VILLALOBOS, C. Mobile Phone Use by the Elderly: relationship between usability, social activity, and the environment. Sustainability, [s.I.], v. 12, n. 7, p. 2690-2703, 30 mar. 2020. MDPI AG. http://dx.doi.org/10.3390/su12072690.

CHIRAYUS, K.; NANTHAAMORNPHONG, A. A Systematic Mapping Review: Mobile User Interface Design Guidelines for the Elderly with Cognitive Impairments. Proceedings Of The 23rd International Computer Science and Engineering Conference. Pucket, p. 35-42, oct. 2019. IEEE. http://dx.doi.org/10.1109/ICSEC47112.2019.8974698.

FA, W.; SOO, K. C. Research on Smart Phone Interfaces for the Elderly Based on Ergonomics. Journal Of Physics: Conference Series, [s.l.], v. 1098, p. 012011, set. 2018. IOP Publishing. http://dx.doi.org/10.1088/1742-6596/1098/1/012011. 
FANG, L. S.; HONG, W. M. High-Aged Using Smart Phone Interface Gesture Operation Research. Advances In Transdisciplinary Engineering, [s.I.], v. 7, n. 40, p. 231-238, 2018. IOS Press. http://dx.doi.org/10.3233/978-1-61499-898-3-231.

FUGLERUD, K. S.; CHAN, R.; SØRLI, H. T. Studying Older People with Visual Impairments Using Mainstream Smartphones with the Aid of the EziSmart Keypad and Apps. Studies In Health Technology And Informatics, [s.l.], v. 256, n. , p. 802-810, jan. 2018. IOS Press. http://dx.doi.org/10.3233/978-1-61499-923-2-802.

GARCIA, A. C.; LARA, S. M. A. Enabling aid in remote care for elderly people via mobile devices: the mobicare case study. Proceedings Of The 8th International Conference On Software Development And Technologies For Enhancing Accessibility And Fighting Info-exclusion Dsai 2018, Thessaloniki, p. 270-277, jun. 2018. ACM Press. http://dx.doi.org/10.1145/3218585.3218671.

GHAYAS, S.; AL-HAJRI, S. A.; SULAIMAN, S. Experimental Study: The Effects of Mobile Phone Icons Characteristics on Users' Age Groups. Journal of Computer Science, [s.l.], v. 14, n. 8, p. 11341143, ago 2018. DOI: http://dx.doi.org/10.3844/jcssp.2018.1134.1143.

GRUPO ĂNIMA EDUCAÇÃO. Manual Revisão Bibliográfica Sistemática Integrativa: a pesquisa baseada em evidências. Belo Horizonte: Ead - Educação A Distância, 2014. 58 p. Disponível em: <http://disciplinas.nucleoead.com.br/pdf/anima_tcc/gerais/manuais/manual_revisao.pdf $>$. Acesso em: 01 abr. 2020.

HOU, G.; DONG, H.; NING, W.; HAN, L. Larger Chinese text spacing and size: effects on older users: experience. Ageing And Society, [s.l.], v. 40, n. 2, p. 389-411, 28 ago. 2018. Cambridge University Press (CUP). http://dx.doi.org/10.1017/s0144686x18001022.

IBGE. 2010. Censo 2010 (2010). Acesso em 26/06/2020. Disponível em: <http://censo2010.ibge.gov.br>.

IIDA, I.; GUIMARÃES, L.B.M. Ergonomia: projeto e produção. 3a. ed. Rio de Janeiro: Edgard Blucher, 2016

JAKKAEW, P.; HONGTHONG, T. Requirements Elicitation to Develop Mobile Application for Elderly. 2017 International Conference on Digital Arts, Media and Technology (ICDAMT). Chiang Mai, jan. 2017. IEEE. http://dx.doi.org/10.1109/ICDAMT.2017.7905013.

KOHLBACHER, F.; HERSTATT, C.; SCHWEISFURTH, T. Product Development for the Silver Market. In: KOHLBACHER, F.; HERSTATT, C. (ed.). The Silver Market Phenomenon: Marketing and Innovation in the Aging Society. Berlim, Ed. Springer-Verlag, 2011. p. 03-13.

LAI, L.; LAI, C. Desining interface for Elderly Adults: access from the smartphone to the world. Lecture Notes In Computer Science, [s.I.], v. 9469, n. 1, p. 306-307, jan. 2015. Springer International Publishing. http://dx.doi.org/10.1007/978-3-319-27974-9.

LIU, S.; CHANG, C.; WANG, M.; LAI, H. A Study of the Factors Affecting the Usability of Smart Phone Screen Protectors for the Elderly. Human Aspects Of It For The Aged Population. Design For Aging, [s.I.], v. 9754, n. 1, p. 457-465, jul. 2016. Springer International Publishing. http://dx.doi.org/10.1007/978-3-319-39943-0_44.

MANSSON, L.; WIKLUND, M.; ÖHBERG, F.; DANIELSSON, K.; SANDLUND, M. Co-Creation with Older Adults to Improve User-Experience of a Smartphone Self-Test Application to Assess Balance Function. International Journal Of Environmental Research And Public Health, [s.I.], v. 17, n. 11, p. 3768, 26 maio 2020. MDPI AG. http://dx.doi.org/10.3390/ijerph17113768.

MENDES, M. R.S.S. B.; GUSMÃO, J. L.; FARO, A. C. M.; LEITE, R. C. B. O. A situação social do idoso no Brasil: uma breve consideração. Acta paul. enferm. [online]. 2005, vol.18, n.4, pp.422-426. ISSN 1982-0194. https://doi.org/10.1590/S0103-21002005000400011.

PASCHOARELLI, L. C. Usabilidade aplicada ao design ergonômico de transdutores de ultrasonografia: uma proposta metodológica para avaliação e análise do produto. 2003, 142 p. Tese (Doutorado) - UFSCar, São Carlos, 2003. 
PASCHOARELLI, L. C.; SILVA, J. C. P. Design Ergonômico: uma revisão dos seus aspectos metodológicos. Conexão - Comunicação e Cultura, v. 5, n. 10. 2006.

\section{PEREZ, I. U.. MANUAL PARA CONDUÇÃO DE REVISÃo BIBLIOGRÁFICA SISTEMÁTICA} (RBS). Bauru, 2020.

SALMAN, H. M.; AHMAD, W. F. W.; SULAIMAN, S. H. Evaluation of the Smartphone Applications in Supporting Elderly. Advances In Intelligent Systems And Computing, [s.l.], v. 843, p. 781-790, 9 set. 2018. Springer International Publishing. http://dx.doi.org/10.1007/978-3-319-99007-1_72.

SHA, C.; LI, R.; CHANG, K. Color Affects the Usability of Smart Phone Icon for the Elderly. Digital Human Modeling. Applications In Health, Safety, Ergonomics, And Risk Management: Health and Safety, [s.I.], v. 10287, n. 2, p. 173-182, jul. 2017. Springer International Publishing. http://dx.doi.org/10.1007/978-3-319-58466-9_17.

SMITH, A. L.; CHAPARRO, B. S. Smartphone Text Input Method Performance, Usability, and Preference With Younger and Older Adults. Human Factors: The Journal of the Human Factors and Ergonomics Society, [s.I.], v. 57, n. 6, p. 1015-1028, 20 mar. 2015. SAGE Publications. http://dx.doi.org/10.1177/0018720815575644.

TZU-NING, W.; PO-LIANG, C.; PO-LUN, C. Evaluate the Usability of the Mobile Instant Messaging Software in the Elderly. Studies In Health Technology And Informatics, [s.I.], v. 245, n. 2017, p. 818-822, 2017. IOS Press. http://dx.doi.org/10.3233/978-1-61499-830-3-818.

UNITED NATIONS. Life Expectancy and Mortality at Older Ages. 2013. Disponível em:<https://www.un.org/en/development/desa/population/publications/pdf/popfacts/PopFacts_20138_new.pdf>. Acesso em: 16/06/2020.

YANG, M.; HUANG, H. Research on Interaction Design of Intelligent Mobile Phone for the Elderly Based on the User Experience. Human Aspects Of It For The Aged Population. Design For Aging, [s.l.], v. 9193, n. 1, p. 528-536, 21 jul. 2015. Springer International Publishing. http://dx.doi.org/10.1007/978-3-319-20892-3_51.

ZAREEI, H.; YUSUFF, R. M.; SALIT, S. M.; S.A.R. S. N.; MOHD, R. H. Assessing the usability and ergonomic considerations on communication technology for older Malaysians. Universal Access In The Information Society, [s.I.], v. 16, n. 2, p. 425-433, 22 jun. 2016. Springer Science and Business Media LLC. http://dx.doi.org/10.1007/s10209-016-0470-3.

ZHAO, Y.; MEN, D. Analysis and Research on the Gesture-Based Interaction of Touch-Screen Smartphones for the Elderly Based on Ergonomics. Advances In Ergonomics In Design, [s.l.], p. 415-426, jul. 2016. Springer International Publishing. http://dx.doi.org/10.1007/978-3-319-41983$1 \_37$.

WORLD HEALTH ORGANIZATION. Ageing and Health. Disponível em: <https://www.who.int/en/news-room/fact-sheets/detail/ageing-and-health>. Acesso em: 15 jan 2020. WORLD HEALTH ORGANIZATION. What is Healty Ageing?. Disponível em: <https://www.who.int/ageing/healthy-ageing/en>. Acesso em: 12 mar 2020. 